Jurnal Kesehatan Masyarakat

\title{
DURATION OF CONTACT, TYPE OF LEPROSY, AND FLOOR CONDITION AS RISK FACTORS FOR LEPROSY SERO-POSITIVITY
}

\author{
Muhamad Zen Rahfiludin ${ }^{1}$, Lintang Dian Saraswati ${ }^{2 凶}$, and Praba Ginandjar ${ }^{2}$ \\ ${ }^{1}$ Department of Public Health Nutrition, Faculty of Public Health, Diponegoro University \\ ${ }^{2}$ Department of Epidemiologi and Tropical Diseases, Faculty of Public Health, Diponegoro University
}

\begin{tabular}{l} 
Article Info \\
\hline Article History: \\
Submitted November 2016 \\
Accepted November 2017 \\
Published November 2017 \\
\hline Keywords: \\
Seropositive Leprosy; \\
House Floor Condition; \\
Duration of Contact. \\
\hline DOI \\
http://dx.doi.org/10.15294/ \\
kemas.v13i2.7791
\end{tabular}

\begin{abstract}
The high number of leprosy seropositivity in a population may lead to clinical leprosy. This study aimed to identify risk factors of leprosy. This study was conducted in Brondong, Lamongan, East Java. The subjects were 153 people who lived with leprosy patient. $\operatorname{lgM}$ anti PGL-1 level was examined used ELISA (Dako). Logistic regression was conducted to test the independent variables. The results showed that the subjects had an average age 31 year $( \pm 6.5)$, average BMI $22( \pm 2.9)$ and average IgM anti PGL-1 level 1041 unit $/ \mathrm{ml}( \pm 820) .79 .7 \%$ of the research subjects were women. The subjects' house floor condition ( $p$ value 0.009 ) was the most influential variable to seropositivity of leprosy. Our findings indicated that not only the duration of leprosy and the contacts need to be considered in the transmission of leprosy, but also environmental factors, such as the subjects' house floor condition.
\end{abstract}

\section{Introduction}

Leprosy, a chronic infectious disease caused by Mycobacterium leprae which primarily affects the skin and nerves, is one of a public health problem worldwide (World Health Organization, 2012; Durrheim, 2002; Lastória, 2014a; Lavania, 2008). New cases of leprosy continue to occur until now. The transmission of leprosy is believed to be caused by droplet discharge of bacilli through nose and mouth to a large extent and to a lesser extent by direct contact of susceptible host with a patient for a long duration. Transmission of leprosy is accepted to be primarily person-toperson and the risk of developing leprosy is 5-10 times higher if one family member had previously contracted leprosy (Kerr-Pontes, 2006). Although a family contact increases the risk of leprosy, in a typical endemic area the majority of new cases cannot be linked to intradomiciliary contact with a leprosy patient. This suggests the existence of unrecognized humanto-human contacts or more intriguing other modes of transmission (Kerr-Pontes, 2006). Deformities caused by the infection create a social stigma attached to leprosy patients untill now.

India, Brazil, and Indonesia are three countries with the highest number of leprosy case in the world. Indonesia has successfully implemented control measures due to effective chemotherapy (MDT). Whereas India and 
Brazil have succeeded in decreasing the number of new cases of leprosy, the number of new cases in Indonesia remains stable (World Health Organization, 2012). This condition is probably due to the high number of seropositive leprosy (a circumstance when a human has higher level of IgM and PGL-1 but the clinical symptom of leprosy is not yet seen) among the population which may lead to clinical leprosy. The development of serologic methods to detect the presence of specific antibodies against $\mathrm{M}$. leprae, increased the findings of seropositive leprosy by contact. A method to detect subject with seropositive leprosy is by examining the Imunoglobulin $\mathrm{M}(\mathrm{IgM})$ anti Phenolic Glycolipid (PGL)-1, known as one of the various way to detect sero-positive leprosy early (Penna , 2016; Düppre, 2012; Silva, 2008; Barreto, 2011). On several literatures, the term sub-clinical leprosy is employed on cases where specific antibodies against M. leprae is found (seropositive) without any manifestation of clinical symptoms of the leprosy itself.

Finding new cases of sub-clinical infections among contacts offers the possibility to provide control measures to reduce the risk of progression into clinical disease with its associated complications and to prevent further dissemination of the disease. In the absence of a method to determine sub-clinical infection with M. leprae reliably, other risk factors for the development of leprosy among contacts need to be identified.

The study was conducted in Brondong, Lamongan, East Java because the trend of leprosy cases increased from 7.34 per 10,000 (2010) to 8.32 per 10,000 (2011), to 14.9 per 10,000 (2012). Based on the type of leprosy, the number MB leprosy cases increased, however the number of $\mathrm{PB}$ leprosy cases remained steady. Brondong sub-district, Lamongan district, located approximately $50 \mathrm{KM}$ from the capital city of Lamongan. The area of Brondong District was $70.13 \mathrm{KM}^{2}$, consisting of ten villages. Brondong sub-district can be categorized into two parts, the coastal areas located in north and agricultural areas in the south. Most Brondong District residents are farmers and fishermen. $80 \%$ of the area is a flat land spreading in eastern, central, northern and western area while $20 \%$ of the land is a plateau, located in the southern region. Hydrological circumstances in the Subdistrict of Brondong is in the form of ground water with a depth averaging 0 to 20 meters above the ground. In certain villages such as Village Tlogoretno Sendangharjo, there was no ground water, so that in dry season there is a shortage was very short of water. The rainy season usually occurs from November to May while the dry season usually occurs in June to October.

The risk factors of leprosy are the duration of exposure, household contact, the type of leprosy, age, sex and socio-economic factors (Lastória, 2014b; Muharry, 2014). Environmental factors, such as overcrowding due to inadequate housing, lead to more frequent close contact with the source of infection and favor the spread of leprosy (KerrPontes, 2006). Economic factors are related to food shortage, thus nutrition status may be related to leprosy. Diet is not considered to play a direct role in the epidemiology of leprosy, but malnutrition may increase the susceptibility to the disease (Rahfiludin, 2007). Studies in Brazil and Bangladesh showed that food shortage was one of the risk factors of leprosy (KerrPontes, 2006; Feenstra, 2011). In both studies, nutrition status was determined by indirect method, inquiring the availability of food to clinical manifestation of leprosy. The study on Leprosy conducted in Semarang revealed the fact that there are leprosy patients who live in their own house with their own family, and those who reside in various orphanages. The detection of a transmission source at home and at some orphanages raise the possibility of finding subclinical seropositive leprosy patient (Rahfiludin, 2007). A study in Malawi included 8741 contacts living in 1656 households among a population of 80,451 people, and found that dwelling contacts of $\mathrm{MB}$ patients had a greater risk of contracting the disease than other household contacts, while such a difference was not seen for contacts of PB patients (KerrPontes, 2006).

Research of the clinical leprosy risk factors have been done frequently. However, research on se seropositive leprosy patients who have not had clinical manifestation of leprosy is still rare. One of the various ways to detect seropositive leprosy early is to measure the level 
of anti PGL-1 IgM. On several literatures the term subclinical leprosy is employed on cases where specific antibodies against M. leprae is found (seropositive) without any clinical manifestation ofleprosy (Rahfiludin, 2007). This research is aimed to identify the relationship between nutritional status measured by body mass index (BMI) and other risk factors (the duration of contact, floor condition, education level, type of leprosy, age, sex and economics status) to seropositive leprosy.

\section{Method}

Our subjects were household contacts who live under one roof and/or partaking food from the same kitchen as the index case (leprosy patients) can be the nuclear family (parents, children or siblings) and others, either multibacillary (MB, contacts of 'cutaneous') or comparable to tuberculoid or paucibacillary (PB).

The subjects were 153 people who met the inclusion criteria as follows: 1) aged 20 to 40 years old, 2) have not shown any leprosy symptom, 3) no consumption of anti-leprosy medicine, 4) no consumption of immunosuppresant in the last three months before blood samples were taken and 5) were willing to participate in the study by signing the informed consent in advance.

Enzyme-linked immunosorbeent assay (Polyclonal rabbit anti human IgM/HRP (Dako) was used in the Examination of IgM anti PGL1 level, conducted in the Institute of Tropical Disease Laboratory, Airlangga University, Surabaya. The cut-off point for seropositivity of IgM anti PGL level was 600 unit/ml (Sujagat, 2015). Five $\mathrm{ml}$ of venous blood was drawn from each subject. The whole blood was centrifuged to separate the serum, which was then stored at $-20^{\circ} \mathrm{C}$. The IgM anti PGL-1 levels of all subjects were noted.

The independent variables for seropositive leprosy were BMI (thin and normal), sex, age (20-30 years old and 31-40 years old), education (elementary, middle, high education), duration of contact (more than five years, and less than or equal to 5 years), the family economics status, house floor condition (soil and ceramics) and the types of leprosy (MB or $\mathrm{PB}$ ). A coding system was used to distinguish between several levels of contact, including the parameters of physical and genetic distance from the subject. For physical distance, the categories were based on the local situation, where most people live in single-room houses. Those who do not share the same house often share the same kitchen-a separate structure on a common compound. Sometimes people live in attached houses, sharing a roof without sharing the same kitchen and garden. These last contacts were considered as more distant than those who share a kitchen but as being closer than other immediate neighbors. The family economic status was observed from the condition of wall, floor, and the power source of electricity in each houses.

Quantified food frequency analysis was performed to determine daily nutrient intake using Nutrisoft software (Nutrition Research and Development Centre, Department of Health, Indonesia). Daily consumption of nutrients (protein, zinc, and vitamin C) was noted and compared with Indonesian recommended nutrient intake to get the proportion of nutrient intake toward recommended nutrient intake.

Before the data was inputted into the logistic model, bivariate analysis was conducted to test the aforementioned nine independent variables. If the Chi-square test showed significant or nearly significant effects ( $p$ value less than 0.05 ), the variable would be the predictor variable in multi logistic regression model and stepwise forward and backward procedures were performed. Finally, the goodness-of-fit test (Hosmer and Lemeshow) showed that the final model was suited to the data. By leaving the least significant variable out of the model, a reduction in value was seen, so this variable was kept in the model. Odds ratio (OR) was calculated.

The study was conducted in Brondong Subdistrict, Lamongan District, East Java, Indonesia. It is located approximately $50 \mathrm{KM}$ from the capital city of Lamongan. The total area of the District Brondong amounted to $70.13 \mathrm{KM}^{2}$ consisting of the ten villages.

The ethical clearance for this study was obtained from Research and Public Service Institute, Airlangga University.

\section{Result and Discussion}

The average age among the subjects was 31 year $( \pm 6.5)$ with average BMI $22( \pm 2.9)$. The 
average level of IgM anti PGL-1 was 1041 unit/ $\mathrm{ml}( \pm 820) .79 .7 \%$ of the sample were women and they were mostly neighbors or not living under one roof with lepers (Table 1). The education levels varied; however there were still subject that did not had any education background (3.3\%). The floor condition was almost similar among subjects; 42 made from soil (27.5\%), 41 cement floor (26.8\%), 27 tile (17.6\%), and 43 ceramics (28.1\%). There were 9 houses with walls made out of board (5.9\%) and 43 mixed board and stone wall (28.1\%). There was no house with a power source of more than 900 watt which indicated the low welfare of the population (Table 2).

Table 1. Means of Age, Bmi And Igm Anti Pgl-1 Level

\begin{tabular}{lc}
\hline \multicolumn{1}{c}{ Variables } & Mean \pm DS \\
\hline Age (year) & $31 \pm 6.5$ \\
BMI & $22 \pm 2.9$ \\
IgM anti PGL-1 level (unit/ml) & $1041 \pm 820$
\end{tabular}

Source : Primary Data

Table 2. Characteristic of Independent Variables of Seropositive Leprosy

\begin{tabular}{|c|c|c|}
\hline Variables & Frequency & Percentage \\
\hline \multicolumn{3}{|l|}{ Education Level } \\
\hline $\begin{array}{l}\text { No education } \\
\text { background }\end{array}$ & 5 & 3.3 \\
\hline Elementary school & 47 & 30.7 \\
\hline Junior high school & 51 & 33.3 \\
\hline Senior high school & 48 & 31.3 \\
\hline Undergraduate & 2 & 1.4 \\
\hline \multicolumn{3}{|l|}{ Floor Condition } \\
\hline Soil & 36 & 23.5 \\
\hline Cement & 44 & 28.8 \\
\hline Floor tile & 30 & 19.6 \\
\hline Ceramic & 43 & 28.1 \\
\hline \multicolumn{3}{|l|}{ Wall Condition } \\
\hline $\begin{array}{l}\text { Not permanent } \\
\text { (board wall) }\end{array}$ & 9 & 5.9 \\
\hline Semi-permanent & 43 & 28.1 \\
\hline Permanent wall & 101 & 66.0 \\
\hline \multicolumn{3}{|l|}{$\begin{array}{l}\text { Source of Power } \\
\text { Electricity }\end{array}$} \\
\hline Sharing from the & 37 & 24.2 \\
\hline $\begin{array}{l}\text { neighbor } \\
450 \text { watt }\end{array}$ & 96 & 62.7 \\
\hline $\begin{array}{l}450 \text { watt } \\
900 \text { watt }\end{array}$ & 20 & 13.1 \\
\hline
\end{tabular}

Source : Primary Data
Most subject with seropositive leprosy were women (83.7\%), normal BMI (93.3\%), low education level (72.1\%) (Table 3$)$. The study also found that $60.6 \%$ of seropositive subjects had a duration of contact of more than five years, and $30.8 \%$ had houses with the floor made from soil. The percentage of low economic status among subjects with seropositive leprosy was slightly higher than middle high (Table 3). It is similar to a previous study in which more than half of the subjects were female $(84.9 \%$ of those who resided in the orphanages and $63.3 \%$ of those who lived in houses (Rahfiludin, 2007). The education level of sub-clinical leprosy patients also as many as subject in previous study which who lived in the orphanage mostly was junior high school, while those who lived at home finished senior high school (Rahfiludin, 2007).

Based on table 3, the bivariate analysis showed that only four variables were significantly correlated $(p<0.05)$ to seropositive leprosy prevalence. Those variables are duration of contact, leprosy type, subject's house flooring condition and economic status. We then performed multiple logistic regression using backward method to analyze which variable is the most influential to seropositive leprosy prevalence, including the four predictor variables. In step 1, only the variable of "leprosy type" was significant $(\mathrm{p}=0.037)$ while other variables, duration of contact, subject's house flooring condition and economic status were not significant $(\mathrm{p}=0.071,0.073$ and 0.153 , respectively). In step 2 , subject's house flooring condition proved to be the most influential variable $(\mathrm{p}=0.009)$ to leprosy seropositivity.

The studies on risk factors for leprosy patients who had clinical manifestation revealed the variables of leprosy type, duration of contact, genetic relationship, age, environment and food availability (Kerr-Pontes, 2006; Feenstra, 2011; Moet, 2006). In those studies, suspected risk factors of leprosy seropositivity were sex, age, economic status, education level, duration of contact with leprosy patients, house flooring condition and nutritional status (Body Mass Index).

Our study showed that age was not correlated to seropositive leprosy. The pattern of age distribution of leprosy in endemic areas is a bimodal curve, which peaked at age 
Table 3. Description of Independent Variables with Seropositive Leprosy

\begin{tabular}{lcccc}
\hline & \multicolumn{2}{c}{ Seropositive Leprosy } & \multicolumn{2}{c}{ Negative Leprosy } \\
\cline { 2 - 5 } & F & $\%$ & F & $\%$ \\
\hline Sex & & & & \\
Male & 17 & 16.3 & 14 & 28.6 \\
Female & 87 & 83.7 & 35 & 71.4 \\
Age & & & & \\
$31-40$ years & 55 & 52.9 & 23 & 46.9 \\
$=<30$ years & 49 & 47.1 & 26 & 53.1 \\
BMI & & & & \\
Underweight & 7 & 6.7 & 3 & 6.1 \\
Normal & 97 & 93.3 & 46 & 93.9 \\
Education & & & & \\
Low & 75 & 72.1 & 28 & 57.1 \\
Middle-High & 29 & 27.9 & 21 & 42.9 \\
Duration of Contact & & & & \\
More than 5 years & 63 & 60.6 & 19 & 38.8 \\
=<5 years & 41 & 39.4 & 30 & 61.2 \\
Floor condition & & & & \\
Soil & 32 & 30.8 & 4 & 8.2 \\
Not soil & 72 & 69.2 & 45 & 91.8 \\
Economic Status & & & & \\
Low & 58 & 55.8 & 17 & 34.7 \\
Middle-high & 46 & 44.2 & 32 & 65.3 \\
\hline Source : Primary Data & & &
\end{tabular}
Source : Primary Data

10 - 14 years and age 30-60 years (Lastória \& Abreu, 2014b). The older the age, the higher the risk of developing leprosy (Moet, 2006). The inconsistency between our study and the previous ones may be due to the age different of subjects used. In the demographic result in Brazil, there was no significant difference in gender, age, colour, or marital status (KerrPontes, 2006). None of the environmental and demographic variables was associated with an increased risk of leprosy (Kerr-Pontes, 2006; Frota, 2010).

The prevalence of leprosy is higher among men than among women, with a ratio of 2:1 (Lastória, 2014b). However, our results showed that sex was not correlated to the prevalence of seropositivity of leprosy. Thus our result supports the Kerr-Pontes study, which also showed no relationship between sex and leprosy (Kerr-Pontes, 2006). Moreover, the Moet study showed the same trend in both sexes (Moet, 2006). Our subjects were aged 20-40 years old. There have been conflicting findings with regard to sex as a risk factor for leprosy. Two studies in India found no difference between males and females, but, in Malawi, the risk was significantly greater for males than for females. Other studies also noted that the attack rate among female contacts was lower than among male contacts (Moet, 2004; Schuring, 2006). It may be concluded from our study that male and female contacts were equally susceptible to contract leprosy and that, for both sexes, people aged 20-29 years old had less risk than those aged 5-19 and more than 30 years old. In addition, many women in Lamongan wear moslem wears which cover their bodies and thus possibly reducing the Table 4. Relationship Between Independen Variables With Seropositive Leprosy

\begin{tabular}{lc}
\hline \multicolumn{1}{c}{ Independent variables } & p-value \\
\hline Age & 0.492 \\
Sex & 0.079 \\
BMI & 0.887 \\
Education level & 0.065 \\
Type of leprosy & 0.011 \\
Duration of contact & 0.008 \\
Economic status & 0.015 \\
Floor condition & 0.002 \\
\hline
\end{tabular}

Source : Primary Data 
chance of skin contact with leprosy agent.

Our study also showed that nutritional status is not correlated to seropositivity of leprosy This is in contrast with another study in Bangladesh which showed that recent food shortage is correlated to leprosy (Feenstra, 2011). This could be caused by several factors. The first is the age of subjects in Bangladesh which ranged from children to 40 years old, while our study subjects ranged from 20 to 40 years. Children and elderly suffering from malnutrition are more susceptible to leprosy than young adults. Second, our study subjects are people with seropositivity leprosy who have not revealed clinical signs, whereas in Bangladesh the subjects are leprosy patients with clinical manifestation. The stage of morbidity of leprosy in our study was low compared to that in the study of Bangladesh. Therefore, it does not affect the body mass index. Third, the data of Feenstra study were obtained by selfreported questionnaires, thus the measurement was subjective (Feenstra, 2011), while our study directly measured subjects' body mass index. Food shortage leading to hunger is a typical characteristic of low-income households (KerrPontes, 2006). This factor could be more directly related to leprosy since individuals who suffered from hunger at least once during the last 10 years are likely to have experienced nutritional deficiencies in previous periods of their life. It is conceivable that inadequate nutrition weakens the immune competence against infection and, thereby, the infection with M. leprae. Alternatively, this variable could represent a marker for other health hazards associated with extreme poverty such as risky behaviour which increased exposure (Kerr-Pontes, 2006). The mean age and BMI of sub-clinical leprosy patients who lived in an orphanages and at home from previous study in Indonesia showed a significant difference in age $(\mathrm{P}$ value $=0.001)$ but no significant difference in BMI level $(\mathrm{P}$ value $=0.699$ ) between both groups of the subclinical leprosy patients. Inadequate food intake due to economical limitation. A person with low food intake would experience an increase in catabolism, causing malnutrition which in turn would cause destruction of barrier protection and the immune system (Rahfiludin, 2007). A low protein intake will cause abnormality of cellular immunity, which is usually shown by the decrease in $\mathrm{T}$ lymphocyte and natural killer cell activity, and interleukin 2 production (Carvalho, 2015; Adalid-Peralta, 2011; Fitness, 2002). Protein is one of the building blocks of complement, which functions to increase phagocytosis and finally increases bacterial lysis. Another important function of protein is as micronutrient carrier, i.e. zinc. Lack of protein would impede micronutrient transport. Moreover, there is a decrease in cytokine production, B cell function (decrease in secreted IgM), complement activity, and cellmediated immunity. M. leprae is an obligate parasite, thus defense mechanism toward $\mathrm{M}$. leprae infection depends mostly on cellular immunity (Fitness, 2002; Frota, 2010). Zinc is very influential to immune response, i.e. natural killer cell, phagocytosis ability of macrophage cells, T-helper and T-cytotoxic cells. Therefore, low zinc intake can disturb cellular and humoral immunity, and correlated with the severity of leprosy (Reinar, 2008; Nagar, 2007; Rahfiludin, 2007). However, this fact was not in line with the higher anti PGL-1 IgM level.

The education level was not correlated with the prevalence of seropositivity of leprosy. Our result supports the previous studies that found education level is not a leprosy risk factor (Feenstra, 2011; Hegazy, 2002). The level of education does not always correlate to the prevalence of disease. This is because the level of education does not necessarily affect a person's knowledge of a disease. In contrary, education is difficult to interpret at a biological level, as those with low education level usually come from the lowest income stratum of a population and, therefore, share many other health hazards, including lack of health education and access to health care. Kerr-Pontes result consider low education as a distant determinant of leprosy (Kerr-Pontes, 2006). A low education level, experience of food shortage at any time in life, and living (10 years previously) in a house with sand/mud floor were statistically associated with an increased risk of leprosy. In the demographic block, there were no significant difference in gender, age, colour, or marital status. None of the environmental and demographic variables was associated with an increased risk of leprosy (Kerr-Pontes, 2006). 
Bivariate analysis revealed that economic status, duration of contact, type of leprosy and house flooring condition are correlated to seropositivity of leprosy. However, in the second step of the multivariate analysis, only duration of contact which is more than five years leprosy type $\mathrm{MB}$ and the soil floor remains as risk factors of leprosy seropositivity.

Floor condition affected the incidence of seropositivity of leprosy. The result is supported by Kerr-Pontes study also showed that living (at least 10 years) in a house with sand/ mud/soil floor was associated to an increase of leprosy risk (Kerr-Pontes, 2006). Our result supported the previous study that viable $M$. Leprae can be detected in soil samples from the houses of people with leprosy (Lavania, 2008). Although there are not many reports of isolation of $M$. leprae from the environment, it has been known to survive for a long period in the soil-using the mouse foot pad technique demonstrated that M. leprae could remain viable in the soil up to 45 days (Desikan, 1977; Desikan, 1995). Presence of M. leprae DNA has also been reported in water samples in Indonesia, where the presence of M. leprae DNA in $47 \%$ of water samples in highly endemic villages in Indonesia (Matsuoka, 2017), in areas of high prevalence of the disease. This study also showed that there was a statistically significant difference in the positivity rates and amount of viable bacilli detected in the soil near patients' residences as compared to other areas of the village which is relatively far from patients' houses (Matsuoka, 2017). It is well known that M. leprae are shed by the patients to the environment during coughing, sneezing and can survive for variable periods depending on environmental conditions such as sunlight, temperature, moisture, etc. In the present study, there was report of M. leprae detection from soil samples collected from an endemic pocket of leprosy at Ghatampur, Kanpur, India (Lavania, 2008). Personal observations in the study area indicate that even the poorest households were kept clean and that inappropriate hygiene is mainly a consequence of living in the poorest areas. If water supply is limited, the housemakers (usually the mother) may practice inappropriate hygiene. M. leprae can survive outside of human body for several months even under unfavourable conditions. It is possible that this behaviour could maintain the M. leprae in soil and facilitate longer contact and transmission to another person (Kerr-Pontes, 2006). Although it is well established that leprosy is associated with poverty, it is important to elucidate aspects of poverty that may enhance the risk of the transmission of M. leprae and/or facilitate the progress from infection to disease (Kerr-Pontes, 2006).

It has often been observed that contacts of patients with MB leprosy have a higher risk than contacts of patients with PB leprosy who, again, have a higher risk than noncontacts (Moet, 2004; Moet, 2006). However, in our study, type MB of leprosy did not significantly affect leprosy seropositivity. This is because both MB and PB can transmit leprosy through household contact. Therefore, household contacts of either MB and $\mathrm{PB}$ are at equal risk of leprosy infection. Our result was in accordance to Douglas' study that household contacts people living in the same house/under one roof with MB or PB leprosy patients were at equal risk to develop leprosy. Nevertheless, the relative hazard value of $\mathrm{MB}$ is higher than $\mathrm{PB}$ (Douglas, 2004). Goulart and Moet showed that people who are in contact with MB leprosy patients are at higher risk than those who are in contact with PB leprosy patients (Goulart, 2008; Moet, 2004). However in Moet's further study, the result showed that household contacts of $\mathrm{PB}$ leprosy with 2-5 lesions had a higher risk than those of PB leprosy with single lesion (Moet, 2006). Our study did not support Goulart and Moet, possibly because we did not further categorize our PB leprosy patients based on the number of lesions. The contacts of patients with PB2 and MB leprosy appeared to have a similar risk. This raises the issue about the degree of infectiousness of patient classified as PB leprosy. This question cannot be answered in the context of the present cross-sectional study.

It has been established that there is an inverse relationship between physical distance from a patient with leprosy and the risk of contracting leprosy for the contacts (Moet, 2004; Moet, 2006). Most contact studies of leprosy have referred to household contacts. Because household contacts often share a common genetic background, differences 
in risk, compared with those of the general population, could be attributed, at least in part, to genetic factors. For half a century, the role of hereditary factors in clinical leprosy development has been considered (Moet, 2006). In general, the longer the exposure of contacts to index cases the greater is the risk of contracting the disease (Lastória, 2014b). The transmission of leprosy occurs when $\mathrm{M}$. Leprae are discharged from the patient's body and enter other person's body. Theoretically, the transmission can occur by prolonged contact with leprosy patients. Thus the presence of family and neighbors who suffered from leprosy is a source of transmission. Previous studies showed that all leprosy patients had a history of long contact with other leprosy patients (Moet, 2006; Durrheim, 2002). However, in our study the duration of contact was not significantly associated to leprosy seropositivity. This could be due to the age of our subjects, which ranged from 20-40 years, meaning that the duration of the contact is short. While the incubation period of leprosy is prolonged (about 20-30 years), it has to be noted that the physical distance was measured according to residence only. It is possible that close relatives who are neighbors spend more time together than unrelated neighbors. Variables reflecting risk factors for person-to-person transmission-such as crowding or sharing the bed or hammock with other household members-in Brazil, did not show a significant association with leprosy (Kerr-Pontes, 2006).

In a review of this topic in 2002, it was concluded that several genes may be involved in susceptibility to leprosy or to a type of leprosy, however, because many of the associations had only been found in small series of patients or in a single population, these findings need to be confirmed in larger studies (Fitness, 2002). It can be concluded, however, that there is accumulating evidences that the risk of developing leprosy is partly genetically determined. The contribution of genetic predisposition to the development of leprosy still remains to be quantified and disentangled from the effect of relatives living closely together.

Conclusion

Our findings showed many similarities of risk factors between leprosy with clinical manifestation and seropositivity of leprosy. Our findings indicated that not only the duration of leprosy and contacts need to be considered in the transmission of leprosy, but also the environmental factors, such as the presence of soil house floor. It is suggested that people who have had a contact with leprosy cases (with clinical manifestation and/or seropositivity of leprosy) to practice prevention from all leprosy risk factors, especially reducing duration of contacts and changing house flooring if it is still made out of soil. Acknowledgments

Our sincere gratitude to Prof. Shinzo Izumi, MD, PhD, and Prof. Dr. Indropo Agusni, MD, DV, Leprosy Study Group of Tropical Disease Center, Airlangga University, Surabaya for the permission of IgM anti PGL-1 assay.

\section{References}

Adalid-Peralta, L. et al. 2011. Mechanisms underlying the induction of regulatory $\mathrm{T}$ cells and its relevance in the adaptive immune response in parasitic infections. Int J Biol Sci, 7(9) : 1412-1426.

Barreto,J.G.etal.2011.Anti-PGL-Iseroepidemiology in leprosy cases: household contacts and school children from a hyperendemic municipality of the Brazilian Amazon. Leprosy review, 82(4) : 358-70.

Carvalho, A.P.M. et al. 2015. Factors associated with anti-phenolic glycolipid-I seropositivity among the household contacts of leprosy cases. BMC infectious diseases, $15: 219$.

Desikan, K. V, 1977. Viability of Mycobacterium leprae outside the human body. Leprosy review, 48(4) : 231

Desikan, K. V \& Sreevatsa, 1995. Extended studies on the viability of Mycobacterium leprae outside the human body. Leprosy review, 66(4) : 287-95. Available at: http://www.ncbi. nlm.nih.gov/pubmed/8637382 [Accessed March 31, 2017].

Douglas, J.T. et al. 2004. Prospective study of serological conversion as a risk factor for development of leprosy among household contacts. Clinical and Diagnostic Laboratory Immunology, 11(5) : 897-900.

Düppre, N.C. et al. 2012. Impact of PGL-I Seropositivity on the Protective Effect of BCG Vaccination among Leprosy Contacts: a Cohort Study. PLoS Neglected Tropical Diseases, 6(6) : 1711.

Durrheim, D.N. et al. 2002. Leprosy in Mpumalanga 
Province, South Africa--eliminated or hidden? Leprosy Review, 73(4) : 326-33.

Feenstra, S.G. et al. 2011. Recent Food Shortage Is Associated with Leprosy Disease in Bangladesh: A Case-Control Study R. O. Phillips, ed. PLoS Neglected Tropical Diseases, $5(5): 1029$

Fitness, J., Tosh, K. \& Hill, A.V.S., 2002. Genetics of susceptibility to leprosy. Genes and Immunity, 3(8) : 441-453.

Frota, C.C. et al. 2010. Seropositivity to AntiPhenolic Glycolipid-I in Leprosy Cases, Contacts and No Known Contacts of Leprosy in an Endemic and a Non-endemic Area in Northeast Brazil. Transactions of the Royal Society of Tropical Medicine and Hygiene, 104(7) : 490-5.

Goulart, I.M.B. et al. 2008. Risk and Protective Factors for Leprosy Development Determined by Epidemiological Surveillance of Household Contacts. Clinical and Vaccine Immunology: CVI, 15(1) : 101

Hegazy, A.A. et al. 2002. Leprosy in a HighPrevalence Egyptian Village: Epidemiology and Risk Factors. International Journal of Dermatology, 41(10) : 681

Kerr-Pontes, L.R. et al. 2006. Socioeconomic, Environmental, and Behavioural Risk Factors for Leprosy in North-east Brazil: Results of a Case-Control Study. International Journal of Epidemiology, 35(4) : 994-1000.

Lastória, J.C. \& Abreu, M.A.M.M. de, 2014a. Leprosy: Review of the Epidemiological, Clinical, and Etiopathogenic Aspects - Part 1. Anais Brasileiros de Dermatologia, 89(2) : 205-18.

Lastória, J.C. \& Abreu, M.A.M.M. de, 2014 b. Leprosy: review of the epidemiological, clinical, and etiopathogenic aspects - part 1. Anais brasileiros de dermatologia, 89(2) : 205

Lavania, M. et al. 2008. Detection of Viable Mycobacterium Leprae in Soil Samples: Insights into Possible Sources of Transmission of leprosy. Infection, Genetics and Evolution, $8(5)$ : 627-631.

Matsuoka, M. et al. 2017. Mycobacterium Leprae DNA in Daily Using Water as a Possible Source of Leprosy Infection. Indian Journal of Leprosy, 71(1) : 61.
Moet, F. et al. 2004. Risk Factors for Development of Clinical Leprosy among Contacts and Their Relevance for Targeted Interventions. Leprosy Review, 75(4) : 310-326.

Moet, F.J. et al. 2006. Physical Distance, Genetic Relationship, Age, and Leprosy Classification Are Independent Risk Factors for Leprosy in Contacts of Patients with Leprosy. The Journal of Infectious Diseases, 193(3) : 346353.

Muharry, A., 2014. Faktor Risiko Kejadian Kusta. KEMAS Jurnal Kesehatan Masyarakat, 9(2) : 174-182

Nagar, N., 2007. Serum Profile Of Zinc, Copper And Magnesium In Lepromatous Leprosy - A Case Control Study.

Penna, M.L.F. et al. 2016. Anti-PGL-1 Positivity as a Risk Marker for the Development of Leprosy among Contacts of Leprosy Cases: Systematic Review and Meta-analysis. PLoS Neglected Tropical Diseases, 10(5) : 0004703.

Rahfiludin, M.Z. et al. 2007. The Difference of Anti Phenolic Glycolipid-1 (PGL-1) Immunoglobulin-M (IgM) Level and Nutritional Intake in Subclinical Leprosy Patients who Reside at Home and in The Orphanage. Medical Journal of Indonesia, 16(4) : 224

Reinar Liv, M. et al. 2008. Interventions for Skin Changes Caused by Nerve Damage in Leprosy. Cochrane Database of Systematic Reviews, (3)

Schuring, R.P. et al. 2006. Association between AntipGL-I IgM and Clinical and Demographic Parameters in Leprosy. Leprosy Review, 77(4) : 343

Silva, R.C. da et al. 2008. The Result Patterns of ML Flow and ELISA (PGL-I) Serologic Tests in Leprosy-Endemic and Non-Endemic Areas. Revista da Sociedade Brasileira de Medicina Tropical, 41 Suppl 2 : 19-22.

Sujagat, A. et al. 2015. Penemuan Kasus Infeksi Kusta Subklinis pada Anak melalui Deteksi Kadar Antibodi (IgM) anti PGL-1. Kesmas: National Public Health Journal, 10(2) : 74.

World Health Organization, 2012. Global leprosy situation, Geneva: World Health Organization. 